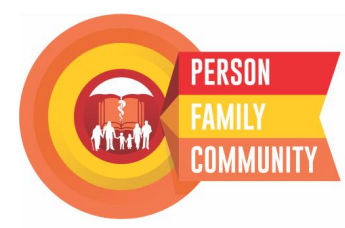

Journal Homepage:

https://jurnal.ugm.ac.id/rpcpe

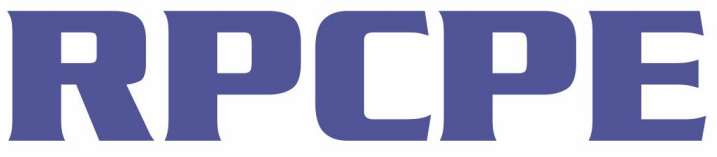

ISSN 2613-943X (print) ISSN 2620-5572 (online)

Review of Primary Care Practice and Education (Kajian Praktik dan Pendidikan Layanan Primer)

\title{
The Effectiveness of IMCI (Integrated Management of Childhood Illness) Mini Training in Improving Health Workers' Skills in Primary Health Centers in Bantul
}

\author{
RR Anugrah Wiendyasari ${ }^{1}$, Hari Kusnanto ${ }^{2}$, Tunjung Wibowo ${ }^{3}$
}

\author{
${ }^{1}$ Bantul District Health Office; Yogyakarta; Indonesia \\ ${ }^{2}$ Departement of Family and Community Medicine; Faculty Medicine, Public Health and Nursing; Universitas Gadjah Mada; Indonesia \\ ${ }^{3}$ Neonatology Division; Department of Child Health; Sardjito General Hospital; Indonesia \\ Corresponding Author: \\ Anugrah Wiendyasari: Bantul District Health Office, Jl. Lingkar Timur, Manding, Trienggo, Kecamatan Bantul, Kabupaten Bantul, \\ Yogyakarta - 55714, Indonesia \\ Email: awiendya@gmail.com \\ To cite this article: \\ Wiendyasari ARR, Kusnanto H, Wibowo T. The effectiveness of IMCI (integrated management of childhood illness) mini training in \\ improving health workers' skills in primary health centers in Bantul. Rev Prim Care Prac and Educ. 2018; 1(3): 129-135.
}

\begin{abstract}
Background: At the Community and Primary Health Care Center in Bantul, the number of paramedics receiving Integrated Management of Childhood Illness (IMCI) training is very limited and not evenly distributed. With the low number of IMCI trained officers, this affects the skill of the officers in conducting the IMCI. Fewer skills affect the handling of sick children including the recognition of general danger signs, classification, designing appropriate action, as well as providing treatment and counseling.Objective: This study aimed to know the effectiveness of IMCI Mini Training intervention to improve health workers' skills in handling sick children with IMCI. Methods: This research was a quasi-experimental study with a non-equivalent pre-post control group design. The sample of this studywas a group of health workers who implement IMCI in daily work at 20 Community and Primary Health Care Centers in Bantul. Data were collected by observing 20 health workers in the control group and 20 health workers in IMCI treatment group before and after receiving IMCI Mini Training. Data results were analyzed using univariate, bivariate and multivariate statistical tests. Results: Using t-test analysis the mean value of health worker's pretest and posttest skill scores in implementing IMCI in control group showed no significant difference $(p=0.857)$ while in the treatment group, the mean value of pretest and posttest score showed a significant difference $(p=0.000)$. In the treatment group, the improvement of sign recognition skills was significant $(p=0.000)$ compared with the classification $(p=0.148)$, treatment $(p=0.009)$, communication and counseling $(p=0.005)$. Multivariate analysis of linear regression showed that IMCI Mini Training was significant in improving the skill of health workers $(p=0.000)$ compared with variables: age $(p=0.970)$, duty $(p=0.425)$, IMCI training history $(p=0.686)$, category of Community and Primary Health Care Center $(p=0.409)$ and education ( $p=0.474)$. IMCI Mini Training improved significantly the sign recognition skills $(p=0.000)$, classification $(p=0.001)$ as well as communication and counseling $(p=0.011)$ but was not significant in treatment skill $(p=0.093)$. IMCI Mini Training can be done in a shorter time and more interactive method by using ICATT. Conclusion: This study showed that IMCI Mini Training increased health workers' skills in IMCI implementation with the advantages of shorter course time, lower cost, and more interactive methods. The IMCI skills were enhanced by the provision of IMCI Mini Training which includes skills in the recognition of common signs, classifications as well as providing appropriate communication andcounseling.
\end{abstract}

Keywords: IMCI, health worker's skill, IMCI Training, Primary Care Center

\section{BACKGROUND}

The quality of the Integrated Management of Childhood Illness (IMCI) system is highly affected by the skills of health workers especially in their ability in illness detection by recognition of danger signs described by the patient or care providers/parents, the treatment skill and ability to communicate and educate appropriately using standards MCE indicators ${ }^{1,2}$. 
To have a good IMCI implementation result, there are some systematic steps which need to be taken, such as creating development training methods, further enhanced training, post-training monitoring, IMCI form availability assurance, availability of drugs and tools for IMCI, technical guidance, etc. ${ }^{3,4}$. IMCI training conducted by the Indonesian Ministry of Health usually requires eleven days in total which equals additional cost and time for health workers.

Due to the high cost and extended period of time needed for conventional IMCI training, the World Health Organization (WHO) recommends using more cost-effective training to increase the number of IMCI trained health workers ${ }^{3}$. With this background, the researcher created a revised version of the training which is called IMCI Mini Training and is done within a shorter time, more cost-effective and applies more interactive methods to achieve similar goals. Standard training from WHO usually lasts for 11 days and class format and the practice field with $30 \%$ time allocation has a total time of 80 hours so it is very time and energy consuming while health workers' available time and numbers are limited. In the Community and Primary Health Care Centers in Bantul the number of medical personnel and paramedics have yet to match the current health needs so appointing officers to follow the training time is low. Until now, no training of IMCI has actually been done except in limited activities for fun and for those who have been following the IMCI training since its inception a few years ago. A Mini Training module needed to be developed with effective training methods and fewer time requirements, less cost and more interactive methods. In this study the researcher developed a condensed format for a Mini Training Integrated Management of Childhood Illness (IMCI).

The purpose of this study was to determine the effectiveness of a revised intervention module of the IMCI Mini Training in improving health workers' skills in managing sick children.

\section{RESEARCH METHODS}

This research was a quasi-experimental study with a nonequivalent pre-post control group design. This research was conducted at 20 Community and Primary Health Care Centers in Bantul, Yogyakarta, Indonesia where health workers have applied IMCI.

In this study, the population included those implementing IMCI at 20 Community and Primary Health Care Centers in Bantul Regency. Samples for the research were 40 officers who were then grouped into a control group (20 people) and experimental group (20 people), and who were selected with a non-random method. The health workers who followed this training had never attended training in IMCI before and were appointed by the head of the Community and Primary Health Care Center.

Inclusion criteria for this research were health workers consisting of doctors, nurses and midwives with: 1) of at least 3-year diploma; 2) worked in the Community and Primary Health Care Center as a provider of IMCI service; and 3 ) never received information about IMCI.

The skills of officers were measured using a questionnaire filled in directly by health workers as well as observed directly by the observer both before and/or after training. The observer also rated the skills of health workers before and after training.

Observations were done using a form with four general activities such as general sign recognition (i.e. danger signs), classification, giving treatment, communication and counseling. The score for every part ranged from 0 , to 1 and 2. If no activities were done, then 0 score will be given, if there were $60-80 \%$ activities done, then the score given was 1 , and if the activities were done for about 80 $100 \%$ then the given score was 2 .

The observation I was generated from the pretest scores and observation number II was generated from the posttest scores after Mini Training IMCI for the control and treatment groups.

The observer made observations on the selected health workers in 20 Community and Primary Health Care Centers in Bantul district at the time of the IMCI service. Observations were made during a single day with 3 patients who were sick children being examined in the IMCI. After the participants were observed, they were then invited to attend a Mini Training in IMCI. The Mini Training IMCI lasted for 3 days in the form of an interactive class following the methods of ICATT in the meeting room of the cooperative Fair Bantul. ICATT methods (IMCI Computerized Adaptation Training Tools) are an adaptation of the guidelines to facilitate the IMCI and officers in using the format of IMCI with instruction provided by an expert who is an IMCI facilitator in the Yogyakarta province, namely dr. Prahesti Fajarwati. Table 1 describes the Community and Primary Health Care Center Participants of the Mini Training in IMCI: 
Table 1. Community and primary health care center participants of the mini training IMCI

\begin{tabular}{clc}
\hline No & Name Community and Primary Health Care Center & Category \\
\hline 1 & Community and Primary Health Care Center Srandakan & Village \\
2 & Community and Primary Health Care Center Sanden & Village \\
3 & Community and Primary Health Care Center Pandak 1 & Village \\
4 & Community and Primary Health Care Center Pandak 2 & Village \\
5 & Community and Primary Health Care Center Bantul 1 & Village \\
6 & Community and Primary Health Care Center Bantul 2 & Village \\
7 & Community and Primary Health Care Center Jetis 1 & Village \\
8 & Community and Primary Health Care Center Jetis 2 & Village \\
9 & Community and Primary Health Care Center Imogiri 1 & Village \\
10 & Community and Primary Health Care Center Imogiri 2 & Village \\
11 & Community and Primary Health Care Center Kretek & Village \\
12 & Community and Primary Health Care Center Pundong & Village \\
13 & Community and Primary Health Care Center Sewon 1 & City \\
14 & Community and Primary Health Care Center Sewon 2 & City \\
15 & Community and Primary Health Care Center Banguntapan 2 \\
16 & Community and Primary Health Care Center Kasihan 1 & Village \\
17 & Community and Primary Health Care Center Kasihan 2 & Village \\
18 & Community and Primary Health Care Center Pleret & City \\
19 & Community and Primary Health Care Center Sedayu 1 & Village \\
20 & Community and Primary Health Care Center Sedayu 2 & Village \\
\hline
\end{tabular}

\section{RESULTS}

Characteristics of each group are shown in Table 2.

Table 2. Characteristics of the subject in the control group and treatment group

\begin{tabular}{llccc}
\hline \multicolumn{2}{c}{ Characteristic of subject } & Control & Treatment & $\boldsymbol{p}$ \\
\hline Sex & Man & 0 & 0 & \\
& Woman & 20 & 20 & 0.175 \\
Age & $20-30$ & $2(10 \%)$ & $4(20 \% 0$ & \\
& $>30-40$ & $8(40 \%)$ & $10(50 \%)$ & \\
\multirow{4}{*}{ Length of service } & $>40$ years & $10(50 \%)$ & $6(30 \%)$ & 0.507 \\
& $<20$ years & $12(60 \%)$ & $14(70 \%)$ & \\
Training & $\geq 20$ years & $8(40 \%)$ & $6(30 \%)$ & 0.168 \\
\multirow{3}{*}{ PHC } & Ever & $8(40 \%)$ & $4(20 \%)$ & \\
& Never & $12(60 \%)$ & $16(80 \%)$ & 0.451 \\
\multirow{2}{*}{ Study } & City & $3(15 \%)$ & $6(30 \%)$ & \\
& Village & $17(85 \%)$ & $14(60 \%)$ & \\
\hline
\end{tabular}

Univariate analysis of data in Table 2 showed that subjects are a homogenous sample with no statistically significant differences between the treatment and control groups $(p>0.05)$.

The results of bivariate analysis data with the paired scores between pretest and posttest control and treatment group using $t$-tests showed that there was an enhancement of health workers' skills after attending the IMCI Mini Training with a statistically significant value $(p=0.000)$ while the control group with no IMCI training showed no significant change $(p=0.857)$.

Variables of health workers' skill components in implementing IMCI in this study included the skill of general danger sign assessment, classification, and giving treatment, communication and counseling to the child's care provider. Next, the score was compared for each of the health worker's skill sets before and after the IMCI Mini Training (pretest and posttest).

Table 3. The Result of bivariate analysis skill IMCI pre and post test

\begin{tabular}{ccccc}
\hline Groups & Score & Mean & N & Sig \\
\hline \multirow{2}{*}{ General sign recognition } & Pre Test & 17.90 & 40 & 0.000 \\
& Post Test & 22.73 & 40 & \\
\hline
\end{tabular}

The results of bivariate analysis using t-tests with all variables show that assessment of general danger signs reached statistically significant value $(p=0.000)$. 
Table 4. The Result of Bivariate Analysis Skill IMCI difference pre and post test

\begin{tabular}{llccc}
\hline \multicolumn{1}{c}{ Groups } & \multicolumn{1}{c}{ Score } & N & Mean & Sig \\
\hline Classification & Decrease & 3 & 16 & 0.148 \\
& Increase & 14 & 7.5 & \\
Treatment & No change & 23 & 7.3 & \\
& Decrease & 5 & 11.57 & 0.009 \\
& Increase & 15 & & \\
Communication and & No change & 20 & & \\
Counseling & Decrease & 8 & 13.19 & 0.005 \\
& & & & \\
& Increase & 23 & 16.98 & \\
\hline
\end{tabular}

The result of paired data analysis between pretest and posttest in treatment group using Wilcoxon test shows that the increase of health worker's skill in classification, giving treatment, and also communication and counseling did not reach a significant statistic value $(p=0.148 ; p=0.009$; $p=0.005$, respectively).
The results of multivariate analysis showed that the independent variables that affect the dependent variable were group division variables that were measured in the Mini Training with significance $(p=0.000)$ for improving the total score of officers' skills in performing the IMCI in accordance with existing procedures. Multivariate analysis results can be seen in Table 5 .

Table 5. The result of linear regression of IMCI's skill

\begin{tabular}{llcccc}
\hline \multirow{2}{*}{ No } & Variable & $\begin{array}{c}\text { Assessment of } \\
\text { general signs }\end{array}$ & Classification & $\begin{array}{c}\text { Giving } \\
\text { treatment }\end{array}$ & $\begin{array}{c}\text { Communication \& } \\
\text { Counseling }\end{array}$ \\
\hline 1. & Age & 0.812 & 0.868 & 0.963 & 0.940 \\
2. & Group & 0.000 & 0.001 & 0.093 & 0.011 \\
3. & $\begin{array}{l}\text { Length of duty } \\
\text { 4. }\end{array}$ & 0.532 & 0.679 & 0.416 & 0.512 \\
& $\begin{array}{l}\text { History of IMCI } \\
\text { training }\end{array}$ & 0.748 & 0.496 & 0.470 & 0.555 \\
5. & $\begin{array}{l}\text { Category of } \\
\end{array}$ & 0.506 & 0.079 & 0.937 & 0.868 \\
& $\begin{array}{l}\text { Community and } \\
\text { Primary Health }\end{array}$ & & & & \\
6. $\begin{array}{l}\text { Care Center } \\
\text { Education }\end{array}$ & 0.821 & 0.314 & 0.874 & 0.417 \\
\hline
\end{tabular}

The result from multivariate analysis showed that within each group who attended the Mini Training IMCI, the health worker's skill scores increased in general danger sign assessment, classification, communication and counseling reached significant statistic value $(p=0.000$; $p=0.001$ and $p=0.011$, respectively) but the statistical value of giving treatment was not significant $(p=0.093)$.

\section{DISCUSSION}

In order for the application of IMCI to be fulfilled as expected then a systematic step-wise mini module was needed which is comprehensive, covering the development of the tiered system of scaffolding with pre-training, posttraining, and monitoring with the guaranteed availability of the IMCI form, the availability of medicines and appropriate tools, etc ${ }^{5}$. Based on the result of the $t$-test in the control group, there was no enhancement of health workers' skills, and in some cases, there were actually decreases of the health worker's skill score. There are many factors that contribute to the IMCI implementation quality in Community and Primary Health Care Centers, such as lack of motivation and concern for IMCI and lack of motivation to provide the best services to patients which can result in inaccuracy of sick child sign identification and failure to recommend appropriate quality treatment and followup ${ }^{4}$.
According to Patel $^{6}$, IMCI is an ideal procedure applied to improve the health of children under five years old but in practice there are some protocols and practices that are not in accordance with the proposed schemata for this workflow, and this is caused by many factors including the workload of the Community and Primary Health Care Center work unit which can be excessive.

For example, the status of nutrition level is rarely measured by health workers although they could see some indications from the weight of the child, resulting in malnutrition disease in children remaining unidentified. Suggestions to improve the quality food intake for babies is also very rare and, in some Community and Primary Health Care Centers, instead the sick child is referred to the nutritionist to get advice in improving a baby's food intake.

Other causes of hindrances in properly implementing IMCI with the full protocol are the time limitation, length of patient's queue and lack of health workers' skills. Also, there are health workers who also do not follow the procedures in order to save time, for instance: counting of breath frequency without proper procedures ${ }^{4}$.

To improve the performance of health workers, it is recommended to be familiar with the national guidelines, ensuring that health workers in practice are working with evidence-based procedures, participating in professional 
training and ongoing technical refreshers to ensure the continual improvement of quality health services provision $^{7}$.

Based on the t-test result in the treatment group, the increase of health worker's skill score in the assessment of general danger signs reached a statistically significant value. IMCI training is one of the effective methods to increase health workers' skills despite taking more time to increase the quality of IMCI implementation ${ }^{5}$. The results of this study are in accordance with some studies done in Tanzania ${ }^{8}$ and Uganda ${ }^{9}$.

A significant difference was seen between IMCI training and non-IMCI health workers' observations in sick children, classification, and treatment of diseases of children, as well as in the communication with the care providers of the sick children.

After IMCI training was given to health workers, the skills and general competencies in the management of sick children and quality of services were improving ${ }^{4}$.

The skill scores of classification in the pretest and posttest of the treatment group were not statistically significant. One reason for the health workers who were not to be able to classify the danger signs correctly was because they did not ask the appropriate question about the symptoms accurately. The accuracy of diagnosing to classify the serious disease (acute or chronic) depends on health workers' skills to identify specific signs for those categories. The lack of a health worker's skill could cause a wrong diagnosis and treatment ${ }^{10}$.

The differences between pretest and posttest skill score in giving treatment were not statistically significant because most of the health workers had known the rule of giving antibiotics for therapy rationally. This result is different compared to the study by Amaral et al. ${ }^{1}$. The rule of using drugs rationally in Bantul has been implemented well. Antibiotics can only be given for pneumonia. But for treatment using IMCI procedures, it is withheld except for emergencies ${ }^{1}$.

IMCI skill scores in communication and counseling pretest and posttest were not statistically significant. There was an improvement of communication skill in the followup visit, giving fluid including breast milk and feeding recommendation. But some health workers did not use the established counseling chart for feeding recommendations for healthy and sick children to properly educate the care providers about the causes of severe and mild malnutrition.

The independent variable of age did not influence the increase of IMCI skill score because when the observation was done, there was no difference between the 30 years old health workers compared to the ones more than 50 years old. Age did not affect a person's compliance with procedures in this case the compliance of the MTBS algorithm $^{11}$.

Length of service in the Community and Primary Health Care Center for each health worker also did not influence the increase of health worker skill score. This result was similar to a study by Adnan who found there was no significant difference between the length of service and health worker skill score in the management of pneumonia $^{12}$.

History of IMCI training by health workers did not influence the overall increasing of skill score in sick children's management because they only had IMCI training from a long time ago and had never conducted a monitoring and evaluating in implementing IMCI. Oppositely, according to research done by Hafizah and Adnan, knowledge of IMCI proved to have an effect on the improvement of health workers' skills ${ }^{6,12,13}$.

The geographic location of the Community and Primary Health Care Center in the village and in an urban area did not significantly influence the increasing skill score because there was no major difference in tools and equipment for patients. Similar findings have been reported by Adnan where Community and Primary Health Care Centers with complete tools or does not follow with the distribution of IMCI trained health workers ${ }^{12}$. The obedience to IMCI procedures is also influenced by having available the complete set of IMCI tools ${ }^{4}$.

For educational background, there were no differences between diploma and bachelor in the increasing of skill score. In the rule of the Ministry of Health Number 1192/ Ministry of Health/Psr/X/2004, it states that IMCI should be taught in the college curriculum regardless of the degree level. Adnan also concluded that diploma or bachelor did not influence the health worker's skill in the management of pneumonia using the IMCI method ${ }^{12}$.

The only one independent variable found to impact the increase of IMCI skill score was the variable of the group who had been given IMCI Mini Training. The basic principles of the mini training IMCI training used ICATT to facilitate the delivery of material during training even though the application of ICATT at the Community and Primary Health Care Center is still lacking.

In this IMCI Mini Training, the course was followed by 20 persons with 1 facilitator. Course time was only three days instead of 11 days so that the financial resources for the training can also be used for supervision after training ${ }^{14}$. By implementing ICATT for this training all the attendees in the IMCI Mini Training could participate actively during the course. This finding supports the conclusion that the Mini IMCI training is more effective than the conventional training because it needs shorter time so it is more costeffective and involves more active participation. This finding is different compared to the study by Khayati et al. which delivered IMCI training with lectures, simulations, case study and demos with audiovisual methods and claimed to be an effective to increase knowledge, attitude and students' skill ${ }^{15}$.

The improved skills of health workers after the IMCI training need to be properly monitored and evaluated by appropriate supervision of the trained health workers to 
maintain their IMCI skill level which may decrease over time $^{10}$. Decreasing of the skill can be seen by the level of disobedience to the IMCI procedures. Estimated time to conduct follow-up monitoring is about 6-12 months ${ }^{16,17}$ and the WHO recommends internal training and follow-up visits with feedback after training ${ }^{18}$.

From linear regression analysis, providing the IMCI Mini Training will increase IMCI skills including the skill of general danger sign assessment, classification, and also communication and counseling, indicated by the statistically significant values. On the other hand, the variables: age, length of service, history of training, the category of Community and Primary Health Care Center and education background of health worker did not have any statistically significant value but may still be important to consider for quality control reasons. Amaral et al. also concluded that the quality of classification and communication skills after IMCI training are better than untrained health workers but are not the only measured competencies $^{1}$.

This study has several limitations:

a. The control group in this study was not given special treatment so that in a more balanced study it is necessary to give an intervention to the control group in the form of giving IMCI training with different methods.

b. The number of subjects in the study is also limited due to time constraints, the number available, and costs so it takes longer to get more subjects with periodic treatment methods.

c. There is no control of external variables which may affect the increase in skill scores, among others, the availability of facilities and infrastructure after the Mini Training IMCI, as well as extensions to the length of the observation time.

\section{CONCLUSION}

The effectiveness of the IMCI Mini Training is shown to significantly increase the skill score of health workers including skills in general danger sign assessment, classification, and also communication and counseling for sick children. There is a need for a dedicated room for IMCI service because it requires more time which will result in a longer queue. A separate room for addressing the health of mother and child will shorten the queue. It is also suggested a periodic supervision to assess the skills of health workers who are involved in sick child management with the IMCI methods. Future research is necessary to identify other factors that may influence the effective implementation of IMCI in the Community and Primary Health Care Centers in Bantul.

\section{Acknowledgments}

We give thanks to the doctors, midwives and nurses who have helped us to finish this research.

\section{Ethical Approval and Informed Consent}

This study was approved by The Medical and Health Research Ethics Committee (MHREC) of the Faculty of Medicine, Universitas Gadjah Mada, Yogyakarta with reference number KE/FK/082/EC/2016.
Funding

Self-funding.

\section{Availability of Data and Material}

Data and material can be accessed via the corresponding author.

\section{Conflict of Interest}

None.

\section{REFERENCES}

1. Amaral J, Gouws E, Bryce J, Leite ÁJ, Cunha AL, Victora CG. Effect of Integrated Management of Childhood Illness (IMCI) on health worker performance in Northeast-Brazil. Cadernos de Saúde Pública. 2004 Jan;20:S209-19.

2. Naimoli JF, Rowe AK, Lyaghfouri A, Larbi R, Lamrani LA. Effect of the Integrated Management of Childhood Illness strategy on health care quality in Morocco. International Journal for Quality in Health Care. 2006 Jan 19;18(2):134-44.

3. World Health Organization. Department of Child, Adolescent Health, World Health Organization, UNICEF. Handbook IMCI: Integrated management of childhood illness. Geneva: World Health Organization. 2005.

4. Mullei K, Wafula F, Goodman C. A case study of Integrated Management of Childhood Illness (IMCI) implementation in Kenya. 2008.

5. Kesanak. Integrated Management of Childhood Illness (IMCI) In: MOH RI (ed). Jakarta: November 21, 2011.

6. Patel H, Nayak A, Bhalani K, Kotecha I, Singh MP. Rapid Assessment of IMNCI Programme in Bhavnagar District, Gujarat. National Journal of Integrated Research in Medicine. 2013 Nov 1;4(6):54-8.

7. Were W. Pre-service and in-service capacity building: Lessons learned from Integrated Management of Childhood Illness (IMCI). 2014.

8. Armstrong-Schellenberg J, Bryce J, Savigny D, Lambrechts T, Mbuya C, Mgalula L, et al. The effect of Integrated Management of Childhood Illness on observed quality of care of under-fives rural Tanzania. Health Policy Plan. 2004;19:1-10.

9. Kolstad, PR, Burnham G, Kalter HD, KenyaMugisha N, Black RE. The integrated management of childhood illness in western Uganda. Bull World Health Organ. 1997; 75 Suppl 1:77-85.

10. Horwood C, Vermaak K, Rollins N, Haskins L, Nkosi P, Qazi S. An evaluation of the quality of IMCI assessments among IMCI trained health workers in South Africa. PloS One. 2009 Jun 17;4(6):e5937.

11. Smet B. Health psychology. Jakarta: PT Gramedia Widiasarana Indonesia. 1994.

12. Adnan DS, Sitaresmi MN. Evaluation of the implementation of Integrated Management of Childhood Illness (IMCI) in Health Officers in the Management of Pneumonia in Toddlers in Aceh Besar District [Doctoral dissertation]. Yogyakarta: Gadjah Mada University; 2013.

13. Hafizah R, Ismail D. Factors that influence health worker compliance to IMCI algorithm in Pontianak City Health Center [Doctoral dissertation]. Yogyakarta: Gadjah Mada University; 2007.

14. Mayhew M, Ickx P, Newbrander W, Stanekzai H, Alawi SA. Long and short Integrated Management of Childhood Illness (IMCI) training courses in Afghanistan: a cross-sectional cohort comparison of post-course knowledge and performance. International Journal of Health Policy and Management. 2015 Mar;4(3):143.

15. Khayati FN, Haryanti F, Laksnawati IS. The impact of training on the management of children with cough of the health workers' knowledge, attitude and skills in the management of children with cough and breathing difficulties. International Journal of Research in Medical Sciences. 2017 Jan 26;3:47-52.

16. Chaudhary N, Mohanty PN, Sharma M. Integrated management of childhood illness (IMCI) follow-up of basic health workers. The Indian Journal of Pediatrics. 2005 Sep 1;72(9):735-9.

17. Mahanta TG, Trakroo A, Gogoi MP, Bhuyan P, Nirmolia N, Baruah $\mathrm{R}$, Jyotinagar D. Comparison of IMNCI activities amongs frontline workers of health and ICDs sectors in Dibrugarh District of Assam and effect of monitoring and supervision- a process evaluation. Journal of Evolution of Medical and Dental Sciences. 2012;1: 29-37.

18. Gove S. Integrated Management of Childhood Illness by outpatient health workers: technical basis and overview. The WHO Working 
Group on Guidelines for Integrated Management of the Sick Child. Bull

World Health Organ. 1997;75(Suppl.1):7-24. 